\title{
Functionary Mechanism between Demographic Structure and Economic Growth in China Based on Cointegrating Methods
}

\author{
Feixue Huang (Corresponding author) \\ Faculty of Management and Economics, Dalian University of Technology \\ 2 Ling Gong Road, Dalian 116024, China \\ Tel: +86-411-8470-7210Ｅ-mail: software666@163.com \\ Jingqin Su \\ Faculty of Management and Economics, Dalian University of Technology \\ 2 Ling Gong Road, Dalian 116024, China \\ Tel: +86-411-8470-7210 E-mail: jingqin@dlut.edu.cn
}

Received: October 25, $2010 \quad$ Accepted: November 2, $2010 \quad$ DOI: 10.5430/rwe.v1n1p10

The research is financed by the National Science Foundation under Grant No. 71033002; the Ministry of Education of the PRC for young scholar who are devoted to the researches of humanities and social sciences under Grant No. 09YJC790025.

\begin{abstract}
This study's objective was to solve the problem of functionary mechanism between demographic structure transition and economic growth in China using cointegration and vector error correction model. The results are: (1) A long-term co-integration relationship exists among birth rate, infant mortality, real GDP per capita and average wage of workers; (2) According to VECM, the adjustment of the economic system is 0.024 when the fluctuation of birth rate deviates from the equilibrium state; (3) Demographic variables are endogenous in the economic system. The conclusions are: (1) In China high-speed economic growth as well as low stable birth rate should be kept and domestic wealth should be accumulated via escalating the average wage; (2) To reduce the impact of the aging population on economic growth in China, high-qualified people's demand for birth should be stimulated to accelerate the transition of industrial structure from labor-intensive to knowledge-intensive.
\end{abstract}

Keywords: Vector Error Correction Model, Generalized Impulse Response Function, Variance Decomposition, Demographic window of opportunity, Aging population

\section{Introduction}

Researches on the relationship between population and economy can be traced back to the later eighteenth century. No matter classical economic population theory, Malthus theory of population growth or Marxist population theory, they all have emphasized the relationship between population and economy. China is the world's most populous country so the research on the relationship between population and economy has far-reaching significance. Figure 1 is the line chart of China's birth rate, infant mortality, real GDP per capita and average wage of workers from 1952 to 2007. It can be seen from Figure 1 that China's demographic structure changes significantly, but whether the economic structure is the underlying reason that changes demographic structure, and whether the change of demographic structure affects economic structure are both unknown. So the research on the above issues has more practical significance.

In the representative researches on the interrelationship between demographic structure and economic system, Becker(1960) is the scholar who earlier supported the view that birth rate should be an endogenous variable of economic system. Adelman(1963) proved that there was positive relationship between birth rate and revenue through empirical analysis. Heer(1966) got that economic development had double effects on birth rate which were positive direct effect and negative indirect effect processing the data of 41 countries. Soon after, some scholars distinguished the relationships of population and economy between developed and developing countries. The research of Friedlander and Silver(1967) indicated that the relationship of birth rate and revenue in developed countries was positive while in developing 
countries it was negative. These early researches only adopted one population variable--birth rate and one economic variable--income to research the relationship of population and economy. The models were relatively simple so they couldn't accurately depict the complex reality.

Yamada(1995) verified that infant mortality rate and birth rate were joint determined and discovered that real income per capita had negative effect on infant mortality rate and positive effect on birth rate. Kirk(1996) and Van de Kaa(1996) finished the theoretical generalization of the causes of demographic transition and they did empirical analysis on the relations among infant mortality rate, birth rate and economic development from the view of development economics and the results were that there were connected relations among the three variables. These conclusions were based on the foreign data so whether they are applied to the situation of China is yet to be studied.

For the series are nonstationary if we use traditional methods to do estimations, the conclusion that two unrelated variables have significant correlation has no meaning. This paper aims at the interrelationship of demographic structure and economic growth comprehensively adopting ADF test, cointegration test, VEC model, generalized impulse response function and variance decomposition. The paper chooses the annual data of birth rate, infant mortality, real GDP per capita and average wage of workers of China from 1952 to 2007 and obtained a long-term cointegration relation among demographic and economic variables. According to the conclusion from Granger test that there is an inevitable connection existing between cointegration and VECM, we continue to apply VECM to discuss the relationships among variables and apply generalized impulse response function and variance decomposition to prove the endophytism of demographic variables to economic system and explore the data attributes of demographic and economic variables as well as the dynamic equilibrium relations and impacts among them.

\section{Methods and processes}

\subsection{Data source, pretreatment and variables description}

To discuss the relationship between demographic structure change and economic growth in China, four variables are chosen which are birth rate (CSL), infant mortality (SWL), GDP per capita (PGDP) and average wage of workers (PJGZ) selecting the annual data of China from 1952 to 2007. The data sources are "China Statistical Yearbook" published by State Statistics Bureau and related official websites. To eliminate heteroscedastic phenomenon, we get the nature logs of all variables symbolized as $L N C S L, L N S W L, L N P G D P, L N P J G Z$.

\subsection{The interrelations among demographic and economic variables}

To show the quantitative interrelations among demographic and economic variables, Table 1 provides the correlation matrix among $L N C S L, L N S W L, L N P G D P, L N P J G Z$.

From Table 1, birth rate has a high positive correlativity with infant mortality and high negative correlativity with GDP per capita and average wage of workers; Infant mortality has a positive correlativity with birth rate while it has high negative correlativity with GDP per capita and average wage of workers; GDP per capita has a high positive correlation with average wage of workers and certain negative correlations with birth rate and infant mortality; Average wage of workers has a high positive correlativity with GDP per capita and it has certain negative correlativity with birth rate and infant mortality.

\subsection{Cointegration analysis on demographic and economic variables}

For the time series of the chosen variables are nonstationary, traditional theory of econometrics can not be used to get objective and accurate results. So we first test the stationarity of variables and then carry out Granger causality test to certain there are causal relations and execute Johansen cointegration test to get long-term equilibrium relations among variables. The econometric software is Eviews 5.0.

\subsubsection{Unit root test}

First, to ensure the stationarity of the series we conduct unit root test. DF (Dickey-Fuller) test, ADF (Augmented Dickey-Fuller) test and PP (Phillips-Perron) test are commonly used. In this paper, we adopt ADF and PP to test the stationarity of series. Results are shown in Table 2.

As can be seen from Table 2, ADF values and PP values of the original series are all larger than 5\% a critical value, which indicates the series are nonstationary while ADF values and PP values of the first difference of series are all less than $5 \%$ critical values showing the series are stationary. The results show that LNCSL, LNSWL, LNPGDP, LNPJGZ are all integrated of order one marked as I(1). Though they are nonstationary series which can't be used to analyze with traditional methods, they are integrated of the same order so we can do cointegration analysis and build VECM. Before that, we do Granger causality test first. 


\subsubsection{Cointegration test}

Based on conintegration theory, if two series which are integrated of the same order have a cointegration relation, there is a long-term equilibrium relation between them and the spurious regression can be avoided. Cointegration test is mainly used to analyze whether there is a long-term equilibrium relation among variables. According to many kinds of information criterion and Vector Auto-Regression (VAR) model, the results can be seen in Table 3. The optimal lag order is 3 from Table 3. For the lag order of cointegration test is that of first difference of variables so it is equal to the optimal lag order of unconstrained VAR model minus one, then the lag order of co-integration test is 2 .

To research the long-term dynamic equilibrium relation among four variables which are birth rate, infant mortality, GDP per capita and average wage of workers, Johansen maximum likelihood procedure, Johansen and Juselius is adopted. The results can be seen in Table 4 .

From Table 4 we know under 5\% significant level there is only one cointegration relation existing indicating there is a long-term equilibrium relation existing among variables. The cointegration equation is shown as (1) and standard deviations are in the parentheses.

$$
\text { LNCSL }=4.370793 \text { LNSWL-3.787915LNPGDP+1.954199LNPJGZ }
$$

$$
\text { (0.81625) (0.87002) }
$$

From Table 4 and Equation (1) we can confirm that under 5\% significant level all the parameters are significant and pass the econometric test. Cointegration equation (1) shows there is a long-term equilibrium relation among variables.

In Equation (1), if infant mortality falls by $1 \%$, birth rate falls by $4 \%$; With the development of economy, the generation restriction mechanism comes into being, which leads to the further decline of birth rate, that is, if GDP per capita increases by $1 \%$, birth rate falls by $3 \%$; Simultaneously, the increase of average wage of workers can stimulate the demand for birth, that is, if average wage of workers goes up by $1 \%$, birth rate rises by $2 \%$.

Affected by birth peak in the early days of foundation and the period of Culture Revolution:

In one hand, China is in the strategic period of "Demographic window of opportunity" currently, that is, large density in the middle of age population and small density in two heads, which looks like an olive. So China has a plentiful supply of labor force which is helpful for accumulating social wealth. If China wants to extend the strategic period, the birth rate should be maintained declining. From Equation (1) we can know economic growth have an inhibited effect on birth rate, at the same time; economic growth can promote the level of social security and then indirectly let the birth rate down. So China's most important policy choices at the present are to develop economy vigorously and keep low birth rate.

On the other hand, the speed of aging population will be quicker after the middle period of 21 st century and China will experience about half a century aging society from the second decade of the 21 st century to the end of the eighth decade. The increase of the aged population will raise death rate without a doubt, which causes further drop of birth rate, and the aging trend will be more and more intense besides the social burden will be heavier. According to Equation (1), with the rise of GDP per capita, the birth rate will fall down. However the increase of average wage of workers can stimulus the demand for birth and raise the birth rate. Moreover, the people gaining high wages are most high-quality people so their culture of the next generation will promote the transition in China from labor intensive to knowledge intensive. So it has everything to gain and nothing to lose.

As a result, China should gradually increase the average wage of workers and encourage high-quality people's demand for birth around 2020 to accelerate the adjustment of China's industrial structure and withstand the impact of aging population on economic growth.

\subsection{Vector Error Correction Model (VECM)}

Based on Granger theory, a group of variables that have the cointegration relation must have the expression form of VECM. From the previous analysis, there is a cointegration among variables so we build VECM to study the long-term and short-term relations among variables of the system. Equation (1) has shown the long-term equilibrium relation among these four variables while VECM can get the error correction term which reflects the extent deviating from long-term equilibrium in the short term. The lag order of VECM is 2 for it is equal to the optimal lag order of unconstrained VAR model minus one. Table 5 shows the VECM of demographic and economic variables.

To LNCSL, the VEC model is shown as Equation (2):

$\mathrm{D}(\mathrm{LNCSL})=-0.02442058968 *(\mathrm{LNCSL}(-1)-4.383926121 *$ LNSWL(-1)-5.472846238*LNPGDP(-1)+5.416359682*LNPJ GZ(-1)+3.372358866)-0.04400360275*D(LNCSL(-1))+0.3053390188*D(LNCSL(-2))-0.9805125716*D(LNSWL(-1)) 
$+0.4145426828 * \mathrm{D}($ LNSWL(-2))-0.6325783522*D(LNPGDP(-1))-0.0214023733*D(LNPGDP(-2)) $+0.2327032368 * \mathrm{D}(\mathrm{L}$ NPJGZ(-1) $)+0.05037002803 *$ D (LNPJGZ(-2)) + 0.01637738312

In Equation (2) the short-term fluctuation of LNCSL is caused by two parts, one is the direct impacts of differences of LNCSL, LNSWL, LNPGDP, LNPJGZ in the short-term, and the other one is the adjustment of long-term equilibrium relation. Error correction coefficient in Equation (2) is -0.02442058968 and the direction is negative, which indicates when there is a deviation from long-term equilibrium the error correction term plays a negative role in adjusting and it reduces the deviation extent so the system tends to be more and more steady, that is, convergence mechanism that prevents deviating from long-run equilibrium plays a role when the short-term fluctuation of birth rate deviates from long-run equilibrium, the economic system will draw non-equilibrium state back to equilibrium state with the adjustment of 0.02442058968 .

To evaluate Equation (2) we need to do econometric tests of the series distribution (Figure 2), autocorrelations (Table 6), normality (Table 7) and heteroskedasticity (Table 8 ) of residuals.

The result of tests is there are no autocorrelation, normality and heteroscedasticity existing in the residual series of VECM. The result is ideal so the assumptions of VECM in Equation (2) are correct.

\subsection{Granger causality test}

Granger solved the problem whether $\mathrm{x}$ causes $\mathrm{y}$. If $\mathrm{x}$ is helpful for the prediction of $\mathrm{y}$, we can call that $\mathrm{x}$ Granger Causes y. The essence of Granger causality test is to test whether the lagged terms of one variable can be introduced into the equation of other variables. If there are hysteretic effects of other variables on one variable, we call they have Granger causality relations.

In order to test whether $S W L, P G D P$ and $P J G Z$ are the causes of $C S L$, Granger causality test is carried out. Granger test asks for the time series of variables are stationary and if each variable in the system are integrated of order one and there is a cointegration relation, then we can do Granger causality test based on VECM. The lag order of Granger causality test can be obtained from Table 3. The results of the test are shown in Table 9.

From Table 9 we know, under 5\% significant level, LNSWL, LNPGDP, LNPJGZ Granger Cause LNCSL; LNCSL Granger Causes LNSWL; LNSWL Granger Causes LNPGDP; LNPGDP Granger Causes LNPJGZ.

The results of Granger causality test indicate that $L N S W L, L N P G D P, L N P J G Z$ are Granger causes of $L N C S L$, which further proves the rationality of building Equation (1).

\subsection{Impulse response function and variance decomposition}

Empirical analysises above show the data attributes, causality relations, long-term equilibrium relations and error correction mechanism of demographic and economic variables. Generalized impulse response function and variance decomposition can be further used to research on dynamic characteristics which are the impacts of birth rate, infant mortality, GDP per capita and average wage of workers change on themselves.

\subsubsection{Impulse response function}

The basic idea of the impulse response function is to analyze the impact of the impulse of random disturbance unit standard deviation on the current and future values of each endogenous variable. When the generalized impulse response method is adopted if a positive impact is on birth rate, we can get the generalized impulse response functions among birth rate itself, infant mortality, GDP per capita and average wage of workers based on VECM shown in Figure 3:

In Figure 3, the horizontal axis denotes the lag period of impulse (Unit: year), and the vertical axis denotes the response of impulse.

For LNCSL, through the analysis of Figure 3 we can get:

LNCSL itself is steady in the medium term (within seven years) indicating it has it's own regulatory mechanism; in the long term (over eight years) it will maintain steady and low increase;

The positive impact of infant mortality will cause birth rate decline in the short term (within 1 year) and in the subsequent medium term (within two to nine years) it will lead birth rate to rise constantly while in the long term (over ten years) it tends towards stability.

The positive impact of GDP per capita will have negative influence on birth rate in the short term (within three years) and in the medium term (within four to nine years) it will cause the increase of birth rate and in the long term (over ten years) the trend is to be steady.

The positive impact of average wage of workers will give rise to the quick increase of birth rate but in the medium term 
(within three to eight years) it will cause birth rate fall back and in the long term (over nine years) it will tend to stability. Generalized impulse response function of LNSWL, LNPGDP, LNPJGZ could also be analyzed. Here we do not show the details.

\subsubsection{Variance decomposition}

Variance decomposition is to decompose fluctuation of every endogenous variable in the system into parts which are associated with random disturbance terms of equations according to causes and in order to understand the relative importance of random disturbance terms to endogenous variables in the model.

To analyze the contribution rate of each structure impact to endogenous variable and evaluate the importance of different structural impacts so we take the example of LNCSL. The results of Cholesky variance decomposition are shown in Table 10 and Figure 4 to 7.

In Figure 4 to 7, the horizontal axis denotes the lag period (Unit: year), and the vertical axis denotes the contribution rate of each variable to LNCSL (unit: percentage). We can get:

(1) In the short term (within 3 years) the largest contribution rate to LNCSL is from $L N S W L$ and in the medium and long term $L N P G D P$ has the obvious impact on LNCSL;

(2) $L N S W L$ has a quick impact on itself (within one year) and later $L N P G D P$ also has an impact on $L N S W L$ and the impact will last for some time (two to ten years);

(3) To $L N P G D P$, the fluctuation of $L N P J G Z$ is the main cause that affecting its variance change;

(4) $L N P G D P$ has the largest contribution rate on $L N P J G Z$ while LNCSL in the short term (one to three years) has an influence on the variance of $L N P J G Z$.

Based on the results of impulse response function and variance decomposition, the demographic variables - birth rate and infant mortality should be treated as endogenous variables to the economic system and it also proves that it is feasible to analyze the relations of them through adopting VECM.

\section{Conclusions}

The contribution of this paper is to analyze the functionary mechanism between demographic structure and economic growth in China adopting cointegration test, vector error correction model, Granger causality test, generalized impulse response function and variance decomposition and investigate the data attributes of demographic and economic variables and their dynamic equilibrium relationship. We find that:

(1) There are mutual dependence relations among demographic variables--birth rate, infant mortality and economic variables--GDP per capita and average wage of workers;

(2) Birth rate, infant mortality, GDP per capita and average wage of workers are all integrated of order one and they have at least one-way Granger causality relations. By using Johansen cointegration test we can obtain a long-term cointegration relation-Equation (1) indicating that these variables have a long-term equilibrium relation.

(3) VECM provides the error correction term which reflects the extent deviating from long-term equilibrium in the short term. In Equation (2) error correction coefficient is -0.02442058968 and the direction is negative indicating when the short-term fluctuation of birth rate deviates from long-run equilibrium, the economic system will draw non-equilibrium state back to equilibrium state with the adjustment of 0.02442058968 .

(4) According to impulse response function and variance decomposition, demographic variables should be treated as endogenous variables to the system.

Affected by the thought that strength lies in numbers, in the early days of foundation and the period of Culture Revolution birth peak appeared. In one hand, China is in the strategic period of "Demographic window of opportunity" currently, that is to say, China is enjoying the precious demographic bonus, that is, large density in the middle of age population and small density in two heads, which looks like an olive. So China has a plentiful supply of labor force which is helpful for accumulating social wealth. If China wants to extend the strategic period, the birth rate should be maintained falling down. From Equation (1) we can know economic growth have an inhibited effect on birth rate, at the same time; economic growth can promote the level of social security and then indirectly let the birth rate down. So China's most important policy choices at the present are to develop economy vigorously and keep low birth rate.

On the other hand, China will experience about half a century aging society from the second decade of the 21 st century to the end of the eighth decade. As time passed, the speed of the aging population is accelerating. When the aging society is reached, the death rate will rise up without a doubt, which causes further drop of birth rate, and the aging trend 
will be more and more intense, besides the social burden will be more and more heavy. According to Equation (1), with the rise of GDP per capita, the birth rate will fall down. However the increase of average wage of workers can stimulus the demand for birth and raise the birth rate. Moreover, the people gaining high wages are most high-quality people so their culture of the next generation will promote the transition in China from labor intensive to knowledge intensive. So it has everything to gain and nothing to lose.

As a result, China should gradually raise the average wage of workers to promote the accumulation of family wealth at the present stage. When entering the early period of aging society around 2020, high-quality people's demand for birth should be encouraged to accelerate the adjustment of China's industrial structure. And what's more we can withstand the impact of aging population on economic growth.

\section{References}

Adelman, I. (1963). An Econometric Analysis of Population Growth. American Economic Review, 53, 314-339.

Becker, G. S. (1960). An Economic Analysis of Fertility. In Ansley J. Coale (Eds.), Demographic and Economic Change in Developed Countries (pp. 225-256). Princeton, NJ: Princeton University Press.

Friedlander, S. \& Silver, M. A. (1967). Quantitative Study of the Determinants of Fertility Behavior. Demography, 4, 30-70.

Heer, D. M. (1966). Economic Development and Fertility, Demography, 3, 423-444.

Kirk, D. (1996). Demographic Transition Theory, Population Studies, 50, 361-387.

Van de Kaa, D.J. (1996). Anchored Narratives: The Story and Findings of Half a Century of Research into the Determinants of Fertility. Population Studies, 50, 389-432.

Yamada, T. (1985). Causal Relationships between Infant Mortality and Fertility in Developed and Less Developed Countries. Southern Economic Journal, 52, 364-370.

Table 1. Correlation coefficient matrix of the demographic and economic variables

\begin{tabular}{|c|c|c|c|c|}
\hline & LNCSL & LNSWL & LNPGDP & LNPJGZ \\
\hline LNCSL & 1.000000 & 0.623079 & -0.868988 & -0.827012 \\
\hline LNSWL & 0.623079 & 1.000000 & -0.654842 & -0.551440 \\
\hline LNPGDP & -0.868988 & -0.654842 & 1.000000 & 0.984498 \\
\hline LNPJGZ & -0.827012 & -0.551440 & 0.984498 & 1.000000 \\
\hline
\end{tabular}

Table 2. ADF and PP tests of the related variables

\begin{tabular}{|c|c|c|c|c|c|c|}
\hline Variable & $\begin{array}{c}\text { ADF value } \\
\text { PP value }\end{array}$ & $\begin{array}{c}\text { Type } \\
(\mathrm{c}, \mathrm{t}, \mathrm{p})\end{array}$ & $\begin{array}{c}\alpha=1 \% \\
\mathrm{critical} \\
\text { value }\end{array}$ & $\begin{array}{c}\alpha=5 \% \\
\mathrm{critical} \\
\text { value }\end{array}$ & DW & Conclusion \\
\hline LNCSL & -3.361731 & $(\mathrm{c}, \mathrm{t}, 1)$ & -4.137279 & -3.495295 & 1.953796 & nonstationary \\
\hline LNCSL & $-2.877025 \cdot$ & $(\mathrm{c}, \mathrm{t}, 3)$ & -4.133838 & 3.493692 & 1.521471 & nonstationary \\
\hline DLNCSL & -5.872370 & $(\mathrm{c}, 0,1)$ & -3.560019 & -2.917650 & 1.983534 & stationary \\
\hline DLNCSL & $-6.126643 \cdot$ & $(\mathrm{c}, 0,3)$ & -3.557472 & -2.916566 & 1.919856 & stationary \\
\hline LNSWL & -1.436542 & $(\mathrm{c}, \mathrm{t}, 1)$ & -4.140858 & -3.496960 & 1.875725 & nonstationary \\
\hline LNSWL & $-2.252255 \cdot$ & $(\mathrm{c}, \mathrm{t}, 3)$ & -4.133838 & -3.493692 & 1.619456 & nonstationary \\
\hline DLNSWL & -4.766833 & $(\mathrm{c}, \mathrm{t}, 1)$ & -4.144584 & -3.498692 & 1.990641 & stationary \\
\hline
\end{tabular}




\begin{tabular}{|c|c|c|c|c|c|c|}
\hline DLNSWL & $-9.187820 \cdot$ & $(\mathrm{c}, \mathrm{t}, 3)$ & -4.137279 & -3.495295 & 1.912359 & stationary \\
\hline LNPGDP & -1.168446 & $(\mathrm{c}, \mathrm{t}, 1)$ & -4.140858 & -3.496960 & 1.986992 & nonstationary \\
\hline LNPGDP & $-0.825089 \cdot$ & $(\mathrm{c}, \mathrm{t}, 3)$ & -4.133838 & -3.493692 & 1.026668 & nonstationary \\
\hline DLNPGDP & -4.561179 & $(\mathrm{c}, \mathrm{t}, 1)$ & -4.137279 & -3.495295 & 1.664417 & stationary \\
\hline DLNPGDP & $-4.337723 \cdot$ & $(\mathrm{c}, \mathrm{t}, 3)$ & -4.137219 & -3.495295 & 1.664417 & stationary \\
\hline LNPJGZ & -0.228326 & $(\mathrm{c}, \mathrm{t}, 1)$ & -4.137279 & -3.495295 & 2.006002 & nonstationary \\
\hline LNPJGZ & $-0.070886 \cdot$ & $(\mathrm{c}, \mathrm{t}, 3)$ & -4.133838 & -3.493692 & 2.247032 & nonstationary \\
\hline DLNPJGZ & -4.723039 & $(\mathrm{c}, \mathrm{t}, 1)$ & -4.1630 & -3.5066 & 2.010167 & stationary \\
\hline DLNPJGZ & $-8.561427 \cdot$ & $(\mathrm{c}, \mathrm{t}, 3)$ & -4.137279 & -3.495295 & 2.003369 & stationary \\
\hline
\end{tabular}

$\alpha$ : the significant level; c: intercept term; t: trend term; p: lag order; D: first difference; The lag order is based on AIC and SC; DW: DW value of serial correlation.

Table 3 Selection criteria of the VAR lag order

\begin{tabular}{|c|c|c|c|c|c|c|}
\hline \multicolumn{7}{|c|}{ Selection criteria of the VAR lag order } \\
\hline \multicolumn{7}{|c|}{ Endogenous variables: LNCSL } \\
\hline \multicolumn{7}{|c|}{ Exogenous variables: C LNSWL LNPGDP LNPJGZ } \\
\hline \multicolumn{7}{|c|}{ Sample: 1952-2007 } \\
\hline \multicolumn{7}{|c|}{ Included observations: 51} \\
\hline Lag & $\log \mathrm{L}$ & LR & FPE & AIC & $\mathrm{SC}$ & HQ \\
\hline 0 & 16.73919 & NA & 0.035539 & -0.499576 & -0.348060 & -0.441678 \\
\hline 1 & 45.12100 & 51.19856 & 0.012148 & -1.573373 & -1.383978 & -1.500999 \\
\hline 2 & 47.38274 & $3.991298^{*}$ & $0.011567^{*}$ & $-1.622853^{*}$ & $-1.395579 *$ & $-1.536005^{*}$ \\
\hline 3 & 47.41951 & 0.063446 & 0.012020 & -1.585079 & -1.319926 & -1.483756 \\
\hline 4 & 47.83180 & 0.695227 & 0.012311 & -1.562031 & -1.259000 & -1.446234 \\
\hline 5 & 47.93790 & 0.174762 & 0.012764 & -1.526977 & -1.186066 & -1.396705 \\
\hline
\end{tabular}


Table 4 Johansen co-integration test of the related variables

\begin{tabular}{|c|c|c|c|c|}
\hline \multicolumn{5}{|c|}{$\begin{array}{l}\text { Sample (adjusted): } 1954 \text { 2007; } \\
\text { Included observationa: 54; } \\
\text { Trend assumption:Quadratic deterministic trend; } \\
\text { Series: LNCSL LNSWL LNPGDP LNPJGZ }\end{array}$} \\
\hline \multicolumn{5}{|c|}{ Lags interval (in first differences): } \\
\hline $\begin{array}{l}\text { Hypothesized } \\
\text { NO. of CE(s) }\end{array}$ & Eigenvalue & Trace Statistic & $5 \%$ Critical Value & Prob.* \\
\hline None * & 0.446285 & 69.21477 & 55.24578 & 0.0018 \\
\hline At most $1 *$ & 0.408675 & 37.29510 & 35.01090 & 0.0280 \\
\hline At most 2 & 0.141848 & 8.924027 & 18.39771 & 0.5879 \\
\hline At most 3 & 0.012211 & 0.663435 & 3.841466 & 0.4153 \\
\hline
\end{tabular}

Trace test indicates 2 cointegrating eqn(s) at the 0.05 level.

* denotes rejection of the hypothesis at the 0.05 level.

\begin{tabular}{|c|c|c|c|c|}
\hline $\begin{array}{c}\text { Hypothesized } \\
\text { NO. of CE(s) }\end{array}$ & Eigenvalue & $\begin{array}{c}\text { Max-Eigen } \\
\text { Statistic }\end{array}$ & 5\% Critical Value & Prob. $^{*}$ \\
\hline None & 0.446285 & 31.91968 & 30.81507 & 0.0365 \\
\hline At most $1 *$ & 0.408675 & 28.37107 & 24.25202 & 0.0135 \\
\hline At most 2 & 0.141848 & 8.260592 & 17.14769 & 0.5743 \\
\hline At most 3 & 0.012211 & 0.663435 & 3.841466 & 0.4153 \\
\hline
\end{tabular}

Max-eigenvalue test indicates 2 cointegrating eqn(s) at the 0.05 level.

* denotes rejection of the hypothesis at the 0.05 level.

Unrestricted Cointegrating Coefficients (normalized by $b^{\prime * S} 11 * b=I$ ):

\begin{tabular}{|c|c|c|c|c|}
\hline LNCSL & LNSWL & LNPGDP & LNPJGZ & \\
\hline 2.331388 & 10.19001 & -8.831101 & 4.555998 & \\
\hline 2.795896 & -5.973615 & -4.944595 & 5.459826 & \\
\hline 5.693447 & 3.751543 & 6.285452 & -5.000061 & \\
\hline 1.783118 & -0.054805 & 3.916446 & -4.869419 & \\
\hline \multicolumn{5}{|c|}{ Unrestricted Adjustment Coefficients (a): } \\
\hline D(LNCSL) & 0.023817 & -0.042886 & -0.021288 & -0.000643 \\
\hline D(LNSWL) & -0.043612 & 0.010183 & -0.005069 & 0.001697 \\
\hline D(LNPGDP) & 0.013922 & 0.018818 & -0.008921 & 0.005074 \\
\hline D(LNPJGZ) & 0.006881 & -0.040082 & 0.006586 & 0.004212 \\
\hline \multicolumn{2}{|c|}{1 Cointegrating Equation(s): } & Log likelihood & 280.2087 & \\
\hline \multicolumn{5}{|c|}{ Normalized cointegrating coefficients(standard error in parentheses) } \\
\hline LNCSL & LNSWL & LNPGDP & LNPJGZ & \\
\hline
\end{tabular}




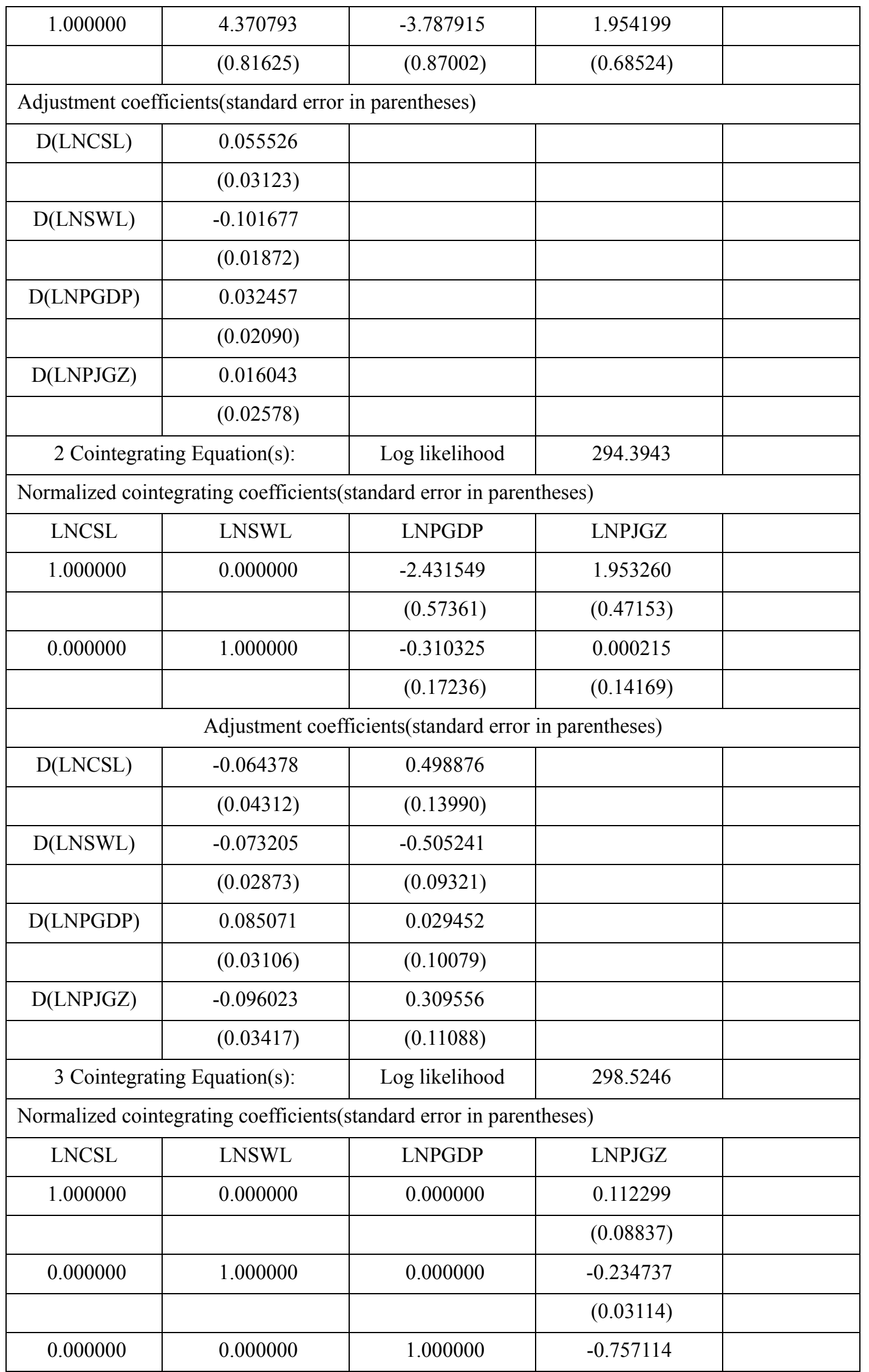




\begin{tabular}{|c|c|c|c|c|}
\hline & & & $(0.04095)$ & \\
\hline \multicolumn{1}{|c|}{ Adjustment coefficients(standard error in parentheses) } & \\
\hline $\mathrm{D}(\mathrm{LNCSL})$ & -0.185579 & 0.419014 & -0.132079 & $(0.13618)$ \\
\hline & $(0.07724)$ & $(0.14166)$ & 0.302931 & \\
\hline $\mathrm{D}(\mathrm{LNSWL})$ & -0.102065 & -0.524257 & $(0.09361)$ & \\
\hline & $(0.05309)$ & $(0.09737)$ & -0.272067 & \\
\hline D(LNPGDP) & 0.034279 & -0.004016 & $(0.10047)$ & \\
\hline & $(0.05699)$ & $(0.10451)$ & 0.178818 & \\
\hline D(LNPJGZ) & -0.058525 & 0.334264 & $(0.11126)$ & \\
\hline
\end{tabular}

Under $1 \%$ significant level, the result of trace test show that there is one cointegration equation while the result of max-eigen test show that there is no cointegration equation. As space is limited, the results are not provided here.

Table 5 Vector Error Correction Model of the related variables

\begin{tabular}{|c|c|c|c|c|}
\hline \multicolumn{5}{|c|}{ Vector Error Correction Estimates } \\
\hline \multicolumn{5}{|c|}{ Sample(adjusted): 19552007} \\
\hline \multicolumn{5}{|c|}{ Included observations: 53} \\
\hline \multicolumn{5}{|l|}{ Standard errors in () } \\
\hline \multicolumn{3}{|c|}{ Cointegrating Eq: } & \multicolumn{2}{|c|}{ CointEq1 } \\
\hline \multicolumn{3}{|c|}{ LNCSL(-1) } & \multicolumn{2}{|c|}{1.000000} \\
\hline \multicolumn{3}{|c|}{ LNSWL(-1) } & $\begin{array}{r}-4.383 \\
(1.079 \\
{[-4.061}\end{array}$ & \\
\hline \multicolumn{3}{|c|}{ LNPGDP(-1) } & $\begin{array}{r}-5.472 \\
(1.110 \\
{[-4.928}\end{array}$ & \\
\hline \multicolumn{3}{|c|}{ LNPJGZ(-1) } & \multicolumn{2}{|c|}{$\begin{array}{c}5.416360 \\
(1.17290) \\
{[4.61794]}\end{array}$} \\
\hline \multicolumn{2}{|r|}{$\mathrm{C}$} & & \multicolumn{2}{|c|}{3.372359} \\
\hline Error Correction: & $D(L N C S L)$ & $D(L N S W L)$ & $D(L N P G D P)$ & $D(L N P J G Z)$ \\
\hline \multirow[t]{3}{*}{ CointEq1 } & -0.024421 & -0.015218 & 0.000879 & -0.066274 \\
\hline & $(0.01634)$ & $(0.01099)$ & $(0.01127)$ & $(0.01188)$ \\
\hline & {$[-1.49409]$} & {$[-1.38469]$} & {$[0.07803]$} & {$[-5.58061]$} \\
\hline \multirow[t]{3}{*}{ D(LNCSL(-1)) } & -0.044004 & 0.489575 & -0.022613 & -0.134410 \\
\hline & $(0.16088)$ & $(0.10817)$ & $(0.11091)$ & $(0.11689)$ \\
\hline & {$[-0.27352]$} & {$[4.52583]$} & {$[-0.20389]$} & {$[-1.14985]$} \\
\hline \multirow[t]{3}{*}{$\mathrm{D}(\operatorname{LNCSL}(-2))$} & 0.305339 & -0.258163 & 0.190499 & 0.007044 \\
\hline & $(0.14413)$ & $(0.09691)$ & $(0.09936)$ & $(0.10472)$ \\
\hline & {$[2.11852]$} & {$[-2.66395]$} & {$[1.91721]$} & {$[0.06727]$} \\
\hline
\end{tabular}




\begin{tabular}{|c|c|c|c|c|}
\hline D(LNSWL(-1)) & -0.980513 & 0.370290 & -0.122615 & -0.340617 \\
\hline & $(0.22368)$ & $(0.15040)$ & $(0.15421)$ & $(0.16252)$ \\
\hline & {$[-4.38347]$} & [2.46201] & {$[-0.79513]$} & {$[-2.09579]$} \\
\hline \multirow[t]{3}{*}{$\mathrm{D}(\operatorname{LNSWL}(-2))$} & 0.414543 & -0.370064 & -0.013656 & -0.300571 \\
\hline & $(0.21268)$ & $(0.14300)$ & $(0.14662)$ & $(0.15453)$ \\
\hline & [ 1.94915] & {$[-2.58783]$} & {$[-0.09314]$} & {$[-1.94509]$} \\
\hline \multirow[t]{3}{*}{ D(LNPGDP(-1)) } & -0.632578 & 0.370750 & 0.601353 & 0.312786 \\
\hline & $(0.20777)$ & $(0.13970)$ & $(0.14323)$ & $(0.15096)$ \\
\hline & {$[-3.04467]$} & [2.65393] & [4.19838] & [2.07199] \\
\hline \multirow[t]{3}{*}{ D(LNPGDP(-2)) } & -0.021402 & 0.150087 & -0.233473 & -0.307088 \\
\hline & $(0.23880)$ & $(0.16056)$ & $(0.16463)$ & $(0.17351)$ \\
\hline & {$[-0.08963]$} & {$[0.93475]$} & [-1.41819] & {$[-1.76990]$} \\
\hline \multirow[t]{3}{*}{ D(LNPJGZ(-1)) } & 0.232703 & -0.248252 & 0.295106 & -0.119603 \\
\hline & $(0.17245)$ & $(0.11596)$ & $(0.11889)$ & $(0.12530)$ \\
\hline & [ 1.34936$]$ & {$[-2.14092]$} & [ 2.48216] & {$[-0.95452]$} \\
\hline \multirow[t]{3}{*}{ D(LNPJGZ(-2)) } & 0.050370 & -0.370108 & 0.045746 & -0.015440 \\
\hline & $(0.16914)$ & $(0.11373)$ & $(0.11661)$ & $(0.12290)$ \\
\hline & {$[0.29780]$} & {$[-3.25429]$} & [0.39231] & {$[-0.12563]$} \\
\hline \multirow[t]{3}{*}{$\mathrm{C}$} & 0.016377 & -0.011593 & 0.034958 & 0.070598 \\
\hline & $(0.02675)$ & $(0.01799)$ & $(0.01844)$ & $(0.01944)$ \\
\hline & {$[0.61225]$} & {$[-0.64458]$} & [ 1.89566$]$ & [3.63238] \\
\hline $\mathrm{R}^{2}$ & 0.523046 & 0.567555 & 0.521453 & 0.641151 \\
\hline Adj. $R^{2}$ & 0.423219 & 0.477044 & 0.421292 & 0.566044 \\
\hline Sum sq. resids & 0.374586 & 0.169351 & 0.178032 & 0.197752 \\
\hline S.E. equation & 0.093334 & 0.062757 & 0.064345 & 0.067815 \\
\hline F-statistic & 5.239501 & 6.270524 & 5.206157 & 8.536409 \\
\hline Log likelihood & 56.03023 & 77.06727 & 75.74249 & 72.95865 \\
\hline AIC & -1.736990 & -2.530840 & -2.480849 & -2.375798 \\
\hline $\mathrm{SC}$ & -1.365236 & -2.159087 & -2.109096 & -2.004045 \\
\hline
\end{tabular}

Table 6 Portmanteau test of the residuals

\begin{tabular}{|c|c|c|c|c|c|}
\hline \multicolumn{6}{|c|}{ VEC Residual Portmanteau Tests for Autocorrelations } \\
\hline \multicolumn{6}{|c|}{ Null Hypothesis: no residual autocorrelations up to lag $\mathrm{h}$} \\
\hline \multicolumn{6}{|c|}{ Sample: 19522007} \\
\hline \multicolumn{6}{|c|}{ Included observations: 53} \\
\hline Lags & Q-Stat & Prob. & Adj Q-Stat & Prob. & df \\
\hline 1 & 3.364288 & $\mathrm{NA}^{*}$ & 3.428986 & NA* & $\mathrm{NA}^{*}$ \\
\hline 2 & 13.82076 & $\mathrm{NA}^{*}$ & 14.29552 & NA* & $\mathrm{NA}^{*}$ \\
\hline
\end{tabular}




\begin{tabular}{|c|c|l|l|l|l|}
\hline 3 & 31.18723 & 0.0127 & 32.70397 & 0.0081 & 16 \\
\hline 4 & 53.90418 & 0.0090 & 57.27537 & 0.0039 & 32 \\
\hline 5 & 63.73460 & 0.0637 & 68.12979 & 0.0295 & 48 \\
\hline 6 & 69.03523 & 0.3112 & 74.10710 & 0.1818 & 64 \\
\hline 7 & 87.43354 & 0.2667 & 95.30515 & 0.1166 & 80 \\
\hline 8 & 97.09431 & 0.4496 & 106.6834 & 0.2142 & 96 \\
\hline 9 & 103.3751 & 0.7078 & 114.2488 & 0.4232 & 112 \\
\hline 10 & 117.7902 & 0.7304 & 132.0163 & 0.3859 & 128 \\
\hline 11 & 123.4180 & 0.8918 & 139.1181 & 0.5993 & 144 \\
\hline 12 & 137.8993 & 0.8961 & 157.8378 & 0.5335 & 160 \\
\hline
\end{tabular}

Table 7 Residual test of normality

\begin{tabular}{|c|c|c|c|}
\hline \multicolumn{4}{|c|}{ VEC Residual Normality Tests } \\
\multicolumn{5}{|c|}{ Null Hypothesis: residuals are multivariate normal } \\
\hline Component & Jarque-Bera & $\mathrm{df}$ & Prob. \\
\hline 1 & 4.990522 & 2 & 0.0825 \\
\hline 2 & 0.301365 & 2 & 0.8601 \\
\hline 3 & 5.017745 & 2 & 0.0814 \\
\hline 4 & 5.399190 & 2 & 0.0672 \\
\hline Joint & 15.70882 & 8 & 0.0467 \\
\hline
\end{tabular}

Table 8 Differences in residual variance test

\begin{tabular}{|c|c|c|c|c|c|}
\hline \multicolumn{6}{|c|}{ VEC Residual Heteroskedasticity Tests: No Cross Terms (only levels and squares) } \\
\hline \multicolumn{6}{|c|}{ Sample: 19522007} \\
\hline \multicolumn{6}{|c|}{ Included observations: 53} \\
\hline \multicolumn{6}{|c|}{ Joint test: } \\
\hline$\chi^{2}$ & df & Prob. & & & \\
\hline 245.5660 & 180 & 0.0008 & & & \\
\hline \multicolumn{6}{|c|}{ Individual components: } \\
\hline Dependent & R2 & $\mathrm{F}(18,34)$ & Prob. & $\chi^{2}(18)$ & Prob. \\
\hline res1*res1 & 0.742117 & 5.435711 & 0.0000 & 39.33221 & 0.0026 \\
\hline res $2 *$ res 2 & 0.630391 & 3.221620 & 0.0016 & 33.41074 & 0.0149 \\
\hline res $3 *$ res 3 & 0.405031 & 1.285882 & 0.2567 & 21.46666 & 0.2565 \\
\hline res4*res4 & 0.703168 & 4.474609 & 0.0001 & 37.26791 & 0.0048 \\
\hline
\end{tabular}




\begin{tabular}{|c|l|l|l|l|l|}
\hline res2*res1 & 0.576672 & 2.573107 & 0.0086 & 30.56360 & 0.0323 \\
\hline res3*res1 & 0.331881 & 0.938287 & 0.5438 & 17.58971 & 0.4830 \\
\hline res3*res2 & 0.572195 & 2.526417 & 0.0097 & 30.32635 & 0.0344 \\
\hline res4*res1 & 0.661820 & 3.696559 & 0.0005 & 35.07644 & 0.0092 \\
\hline res4*res2 & 0.675932 & 3.939794 & 0.0003 & 35.82440 & 0.0074 \\
\hline res4*res3 & 0.546910 & 2.280014 & 0.0187 & 28.98622 & 0.0485 \\
\hline
\end{tabular}

Table 9 Granger Causality Test of the related variables (lag is $n=2$ )

\begin{tabular}{|c|c|c|c|}
\hline Null Hypothesis & Obs & F-Statistic & Prob. \\
\hline $\begin{array}{l}\text { LNSWL does not Granger Cause NLCSL } \\
\text { LNCSL does not Granger Cause LNSWL }\end{array}$ & 54 & $\begin{array}{l}15.0659 \\
7.19392\end{array}$ & $\begin{array}{l}7.9 \mathrm{E}-06 \\
0.00182\end{array}$ \\
\hline $\begin{array}{l}\text { LNPGDP does not Granger Cause } \\
\text { LNCSL } \\
\text { LNCSL does not Granger Cause } \\
\text { LNPGDP }\end{array}$ & 54 & $\begin{array}{l}5.96552 \\
1.70755\end{array}$ & $\begin{array}{l}0.00480 \\
0.19192\end{array}$ \\
\hline $\begin{array}{l}\text { LNPJGZ does not Granger Cause LNCSL } \\
\text { LNCSL does not Granger Cause LNPJGZ }\end{array}$ & 54 & $\begin{array}{l}3.68015 \\
3.44301\end{array}$ & $\begin{array}{l}0.03243 \\
0.03989\end{array}$ \\
\hline $\begin{array}{l}\text { LNPGDP does not Granger Cause } \\
\text { LNSWL } \\
\text { LNSWL does not Granger Cause } \\
\text { LNPGDP }\end{array}$ & 54 & $\begin{array}{l}0.70592 \\
2.39769\end{array}$ & $\begin{array}{l}0.49860 \\
0.10152\end{array}$ \\
\hline $\begin{array}{l}\text { LNPJGZ does not Granger Cause } \\
\text { LNSWL } \\
\text { LNSWL does not Granger Cause } \\
\text { LNPJGZ }\end{array}$ & 54 & $\begin{array}{l}0.19559 \\
0.80208\end{array}$ & $\begin{array}{l}0.82299 \\
0.45419\end{array}$ \\
\hline $\begin{array}{l}\text { LNPJGZ does not Granger Cause } \\
\text { LNPGDP } \\
\text { LNPGDP does not Granger Cause } \\
\text { LNPJGZ }\end{array}$ & 54 & $\begin{array}{l}0.69120 \\
10.5821\end{array}$ & $\begin{array}{l}0.50579 \\
0.00015\end{array}$ \\
\hline
\end{tabular}

Table 10 Cholesky Decomposition of the related variables

\begin{tabular}{|l|l|l|l|l|l|}
\hline \multicolumn{7}{|c|}{ The result of Cholesky Decomposition of LNCSL: } \\
\hline Period & S.E. & LNCSL & LNSWL & LNPGDP & LNPJGZ \\
\hline 1 & 0.093334 & 100.0000 & 0.000000 & 0.000000 & 0.000000 \\
\hline 2 & 0.159491 & 81.41127 & 14.93669 & 3.516742 & 0.135297 \\
\hline 3 & 0.202140 & 72.48264 & 16.44312 & 10.90174 & 0.172499 \\
\hline 4 & 0.236204 & 72.16614 & 12.51504 & 15.16709 & 0.151736 \\
\hline 5 & 0.259754 & 73.39111 & 10.37027 & 15.52771 & 0.710909 \\
\hline
\end{tabular}




\begin{tabular}{|c|c|c|c|c|c|}
\hline 6 & 0.277661 & 74.40936 & 9.099334 & 15.06797 & 1.423343 \\
\hline 7 & 0.294737 & 76.13571 & 8.116927 & 14.09652 & 1.650840 \\
\hline 8 & 0.312608 & 78.05736 & 7.305180 & 12.79620 & 1.841267 \\
\hline 9 & 0.329451 & 79.62622 & 6.586895 & 11.69409 & 2.092800 \\
\hline 10 & 0.345360 & 80.91392 & 6.006626 & 10.83959 & 2.239858 \\
\hline \multicolumn{6}{|c|}{ The result of Cholesky Decomposition of LNSWL: } \\
\hline Period & S.E. & LNCSL & LNSWL & LNPGDP & LNPJGZ \\
\hline 1 & 0.062757 & 9.474410 & 90.52559 & 0.000000 & 0.000000 \\
\hline 2 & 0.120485 & 2.694455 & 90.52466 & 4.210756 & 2.570129 \\
\hline 3 & 0.148951 & 1.789156 & 82.28936 & 8.964705 & 6.956779 \\
\hline 4 & 0.165943 & 1.442180 & 80.71539 & 10.45070 & 7.391725 \\
\hline 5 & 0.185602 & 1.599462 & 81.50726 & 10.54532 & 6.347958 \\
\hline 6 & 0.203413 & 1.827766 & 80.81824 & 11.00981 & 6.344191 \\
\hline 7 & 0.216676 & 1.750698 & 80.27638 & 11.20642 & 6.766502 \\
\hline 8 & 0.230520 & 1.676627 & 80.64329 & 10.99716 & 6.682923 \\
\hline 9 & 0.246022 & 1.663229 & 80.77351 & 10.94595 & 6.617309 \\
\hline 10 & 0.260213 & 1.612347 & 80.41201 & 11.16763 & 6.808006 \\
\hline \multicolumn{6}{|c|}{ The result of Cholesky Decomposition of LNPGDP: } \\
\hline Period & S.E. & LNCSL & LNSWL & LNPGDP & LNPJGZ \\
\hline 1 & 0.064345 & 0.730705 & 6.288764 & 92.98053 & 0.000000 \\
\hline 2 & 0.122812 & 0.202220 & 3.011667 & 94.75193 & 2.034184 \\
\hline 3 & 0.174349 & 0.503086 & 1.701229 & 94.75517 & 3.040518 \\
\hline 4 & 0.214528 & 1.013102 & 1.130567 & 94.12076 & 3.735574 \\
\hline 5 & 0.246469 & 1.188785 & 0.859448 & 94.01693 & 3.934834 \\
\hline 6 & 0.276086 & 1.205198 & 0.980297 & 94.13643 & 3.678077 \\
\hline 7 & 0.307688 & 1.113973 & 1.612587 & 94.15450 & 3.118943 \\
\hline 8 & 0.341904 & 0.995188 & 2.437825 & 93.99915 & 2.567834 \\
\hline 9 & 0.377848 & 0.913784 & 3.275034 & 93.68872 & 2.122465 \\
\hline 10 & 0.414314 & 0.882713 & 4.007542 & 93.33402 & 1.775729 \\
\hline \multicolumn{6}{|c|}{ The result of Cholesky Decomposition of LNPJGZ: } \\
\hline Period & S.E. & LNCSL & LNSWL & LNPGDP & LNPJGZ \\
\hline 1 & 0.067815 & 19.00107 & 4.443316 & 2.363006 & 74.19261 \\
\hline 2 & 0.088348 & 11.66665 & 2.620656 & 30.11310 & 55.59960 \\
\hline 3 & 0.112998 & 7.423462 & 2.104859 & 47.64841 & 42.82327 \\
\hline 4 & 0.144378 & 4.834775 & 4.555744 & 60.59564 & 30.01384 \\
\hline
\end{tabular}




\begin{tabular}{|l|l|l|l|l|l|}
\hline 5 & 0.180646 & 3.208006 & 7.283050 & 68.90466 & 20.60428 \\
\hline 6 & 0.219331 & 2.256555 & 9.343351 & 73.87123 & 14.52887 \\
\hline 7 & 0.259671 & 1.636932 & 11.29323 & 76.43210 & 10.63773 \\
\hline 8 & 0.301504 & 1.218245 & 13.07496 & 77.71377 & 7.993019 \\
\hline 9 & 0.343928 & 0.936768 & 14.49175 & 78.40546 & 6.166020 \\
\hline 10 & 0.386619 & 0.741315 & 15.70471 & 78.67186 & 4.882115 \\
\hline
\end{tabular}

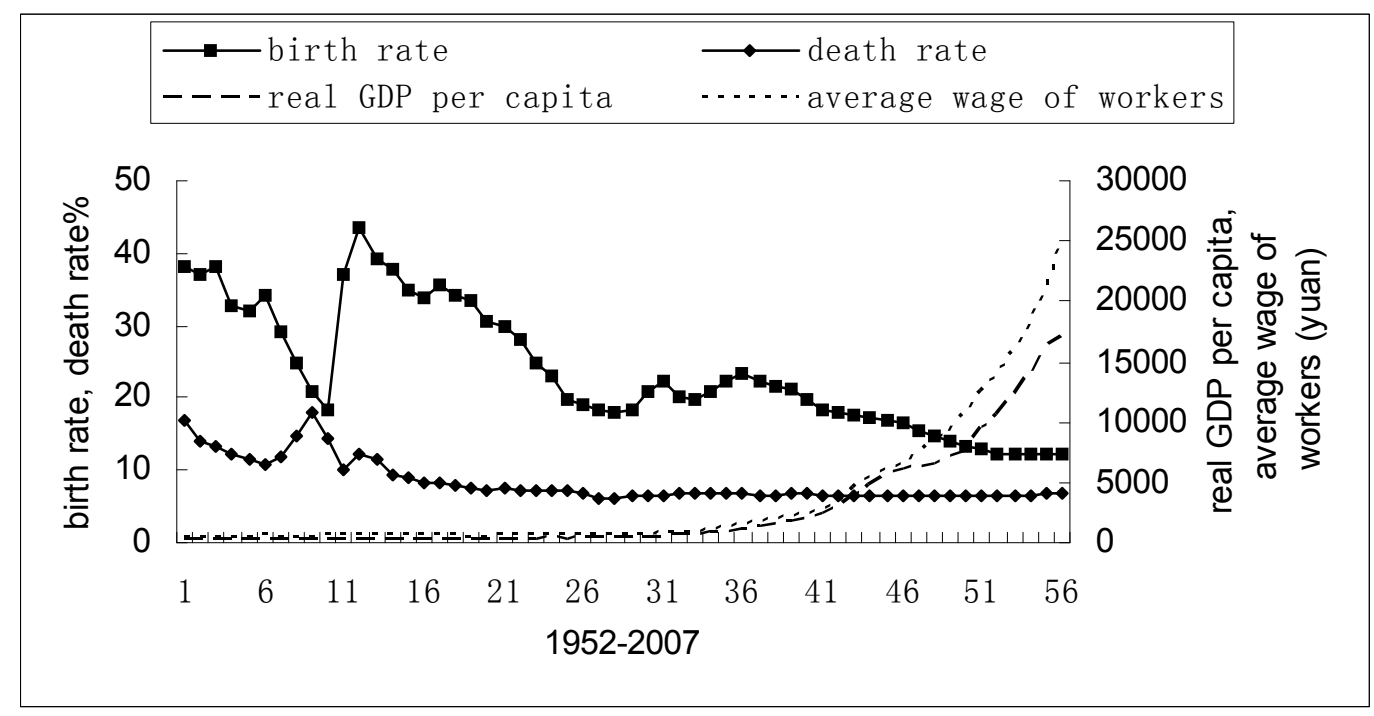

Figure 1 Line chart of birth rate, infant mortality, real GDP per capita and average wage of workers in China from 1952-2007 
LNCSL Residuals
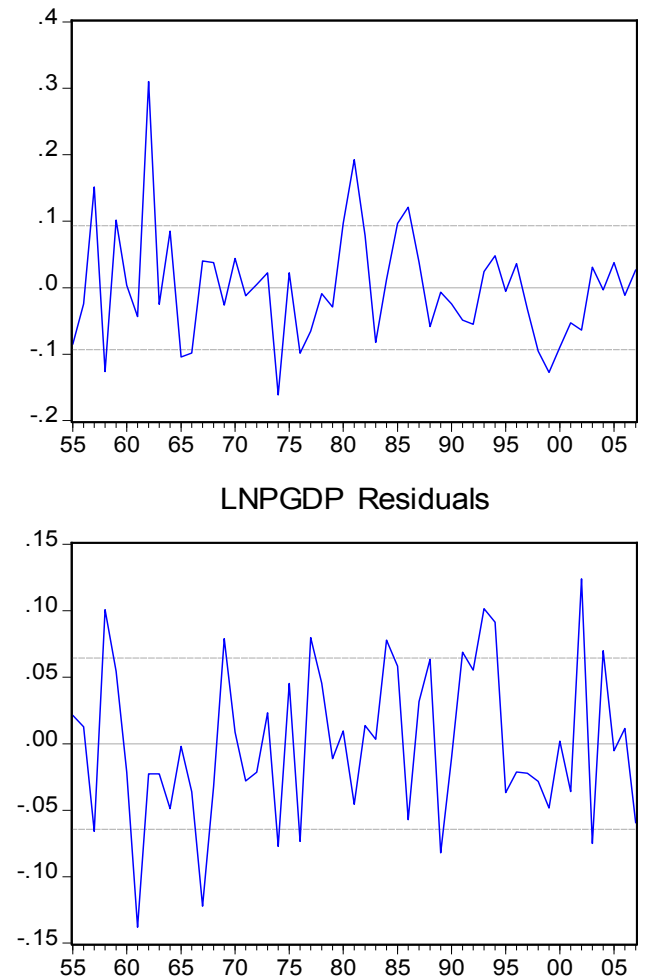

LNSWL Residuals
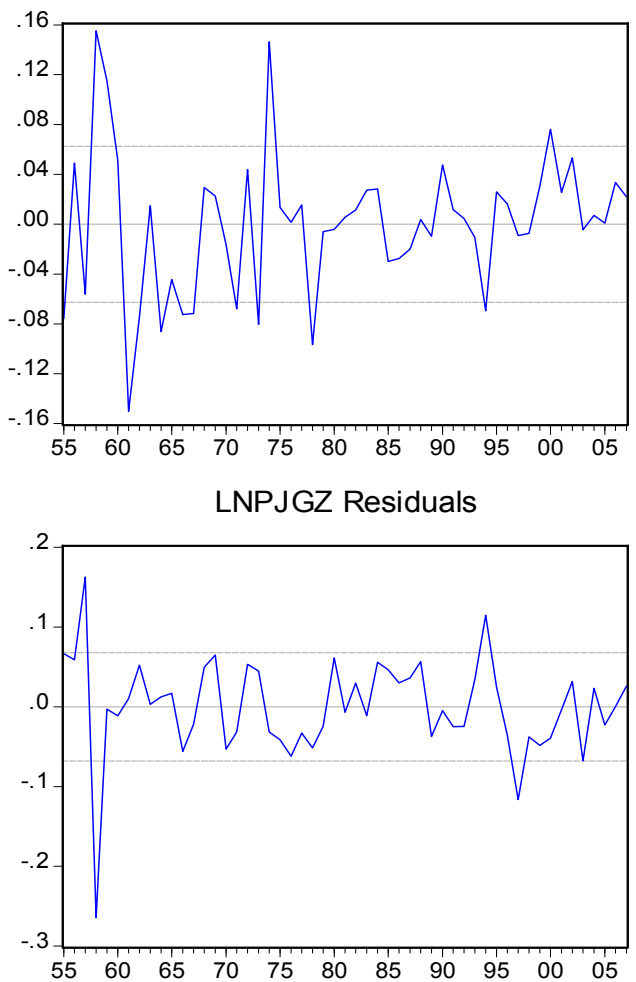

Figure 2 Residuals of the Vector Error Correction Model

Response to Generalized One S.D. Innovations

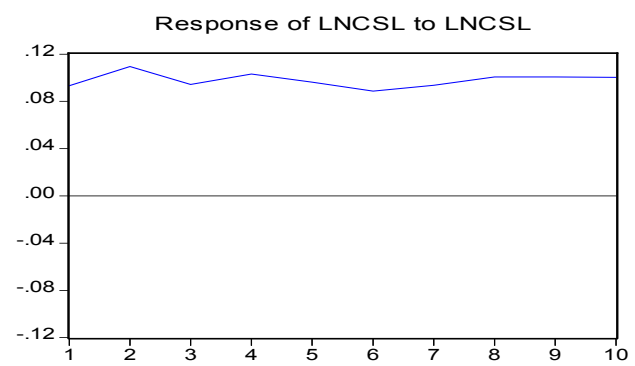

Response of LNCSL to LNSWL
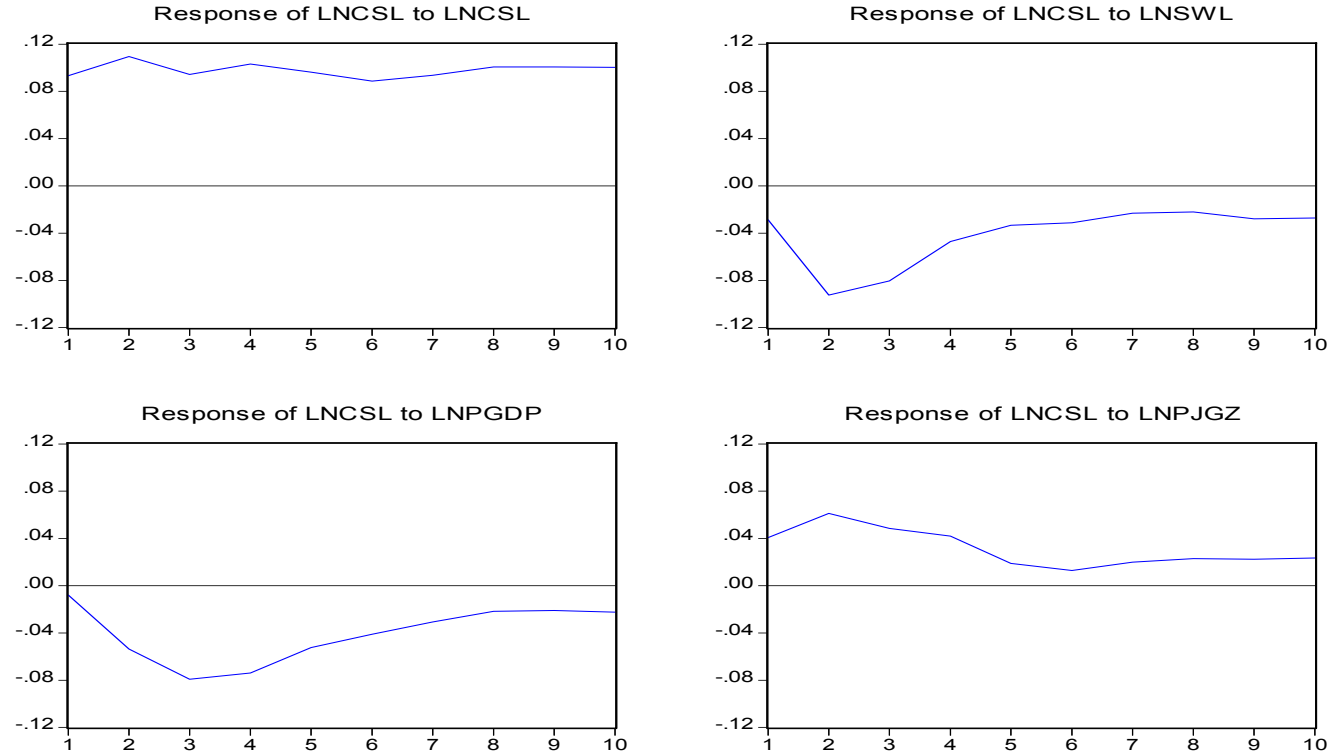

Figure 3 Generalized impulse response function of LNCSL 


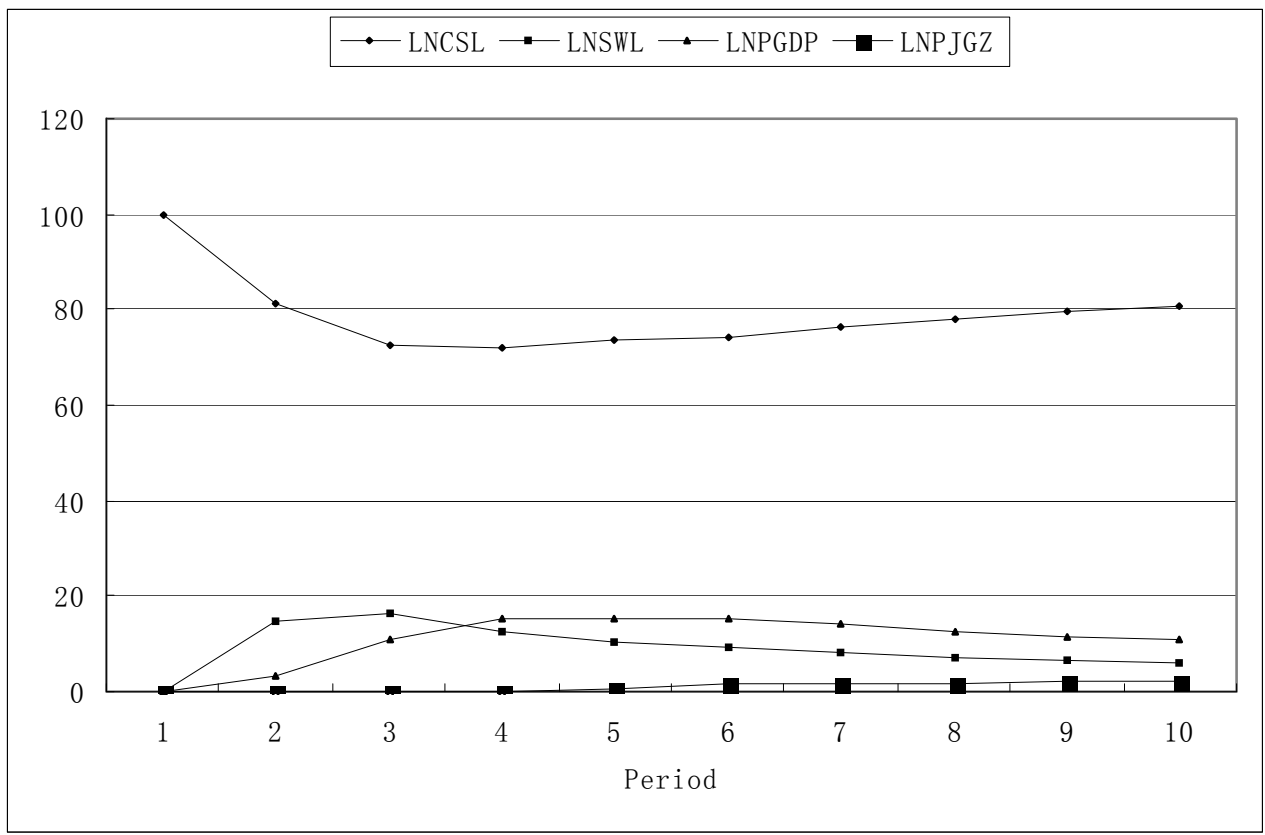

Figure 4 Variance Decomposition of LNCSL

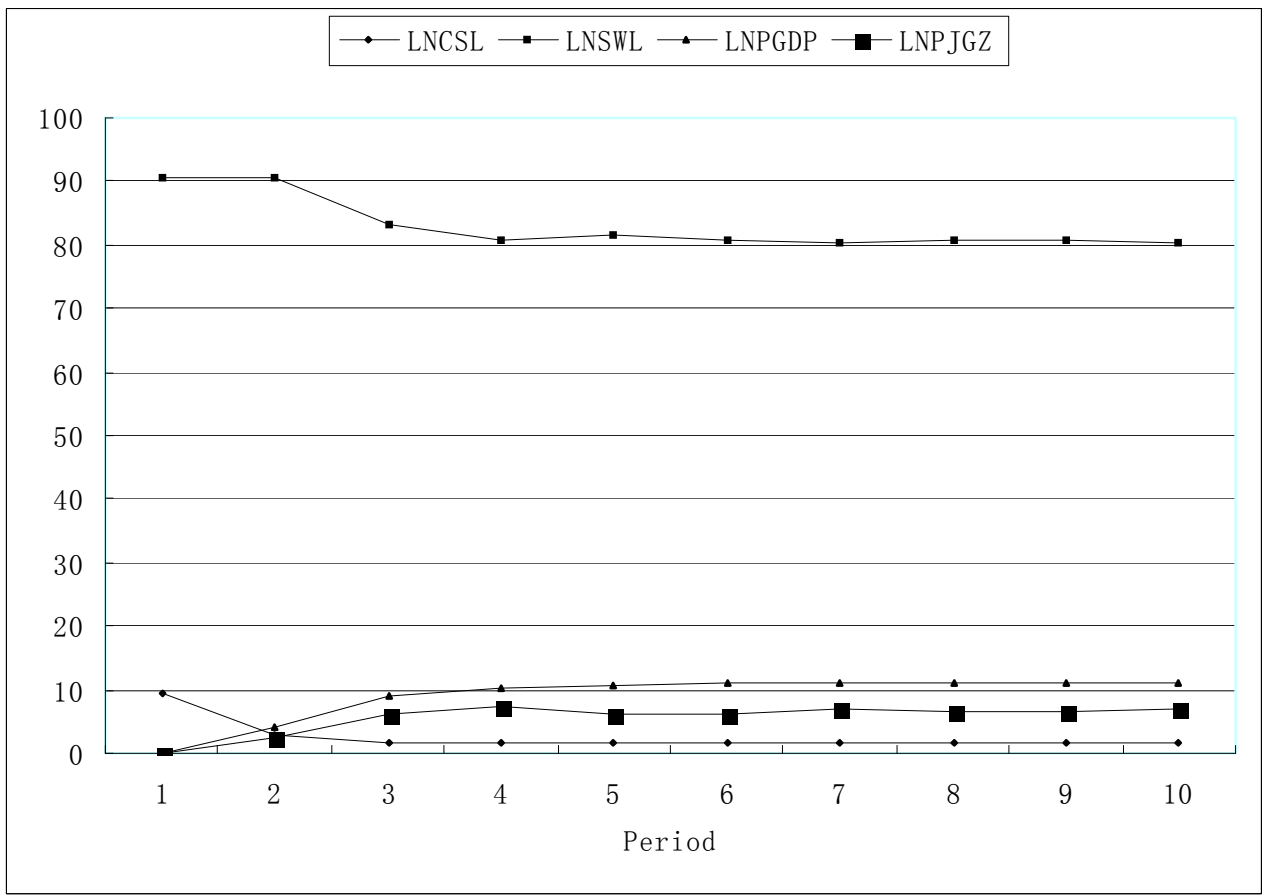

Figure 5 Variance Decomposition of LNSWL 


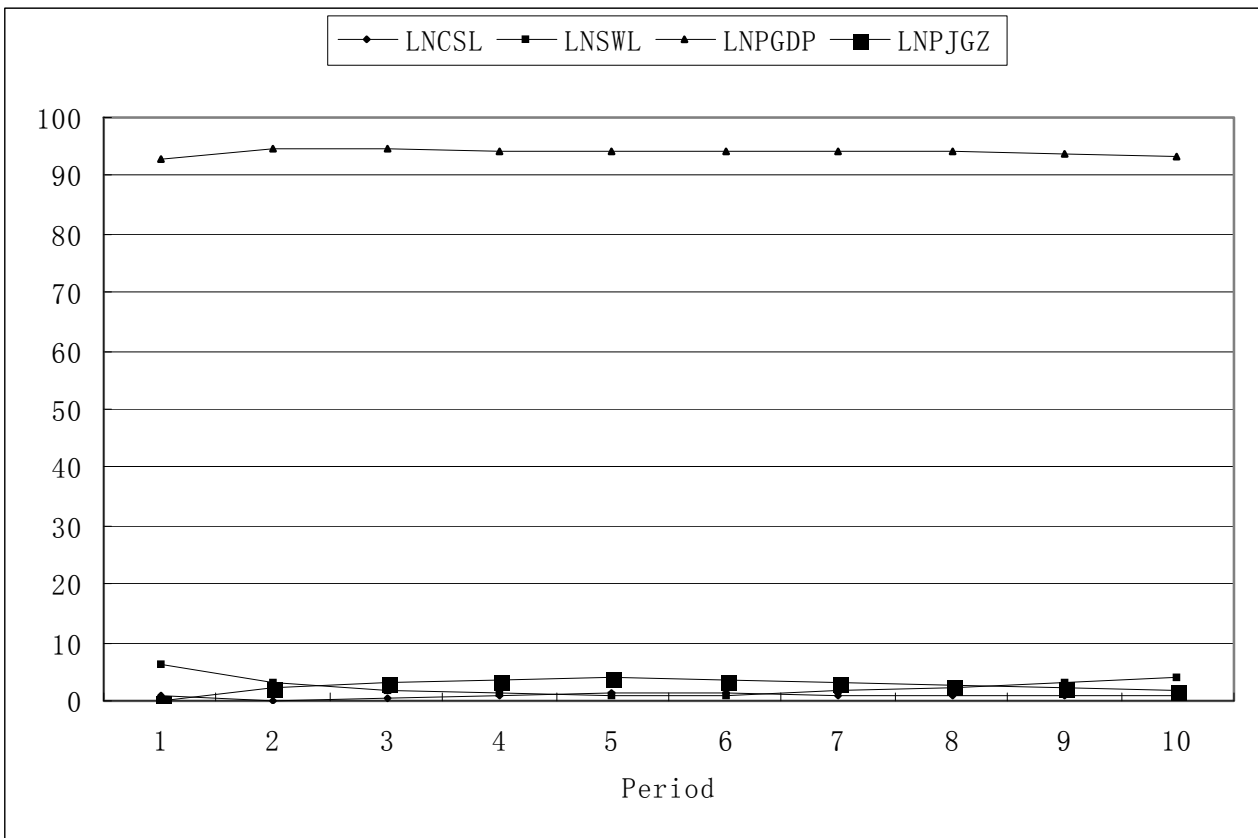

Figure 6 Variance Decomposition of LNPGDP

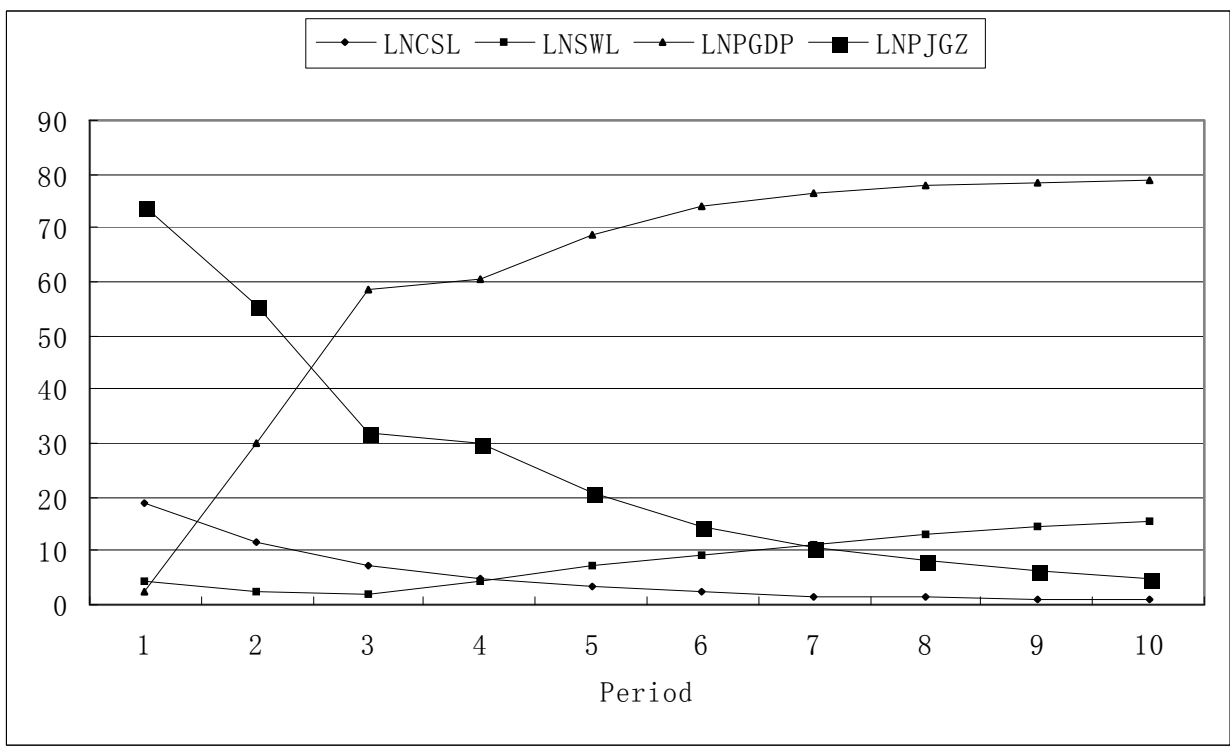

Figure 7 Variance Decomposition of LNPJGZ 